\title{
Carborane-Based Metal-Organic Framework with High Methane and Hydrogen Storage Capacities
}

Robert D. Kennedy, ${ }^{\dagger}$ Vaiva Krungleviciute, ${ }^{\ddagger}, \S$ Daniel J. Clingerman, ${ }^{\dagger}$ Joseph E. Mondloch, ${ }^{\dagger}$ Yang Peng,,$\$$, Christopher E. Wilmer, ${ }^{\perp}$ Amy A. Sarjeant, ${ }^{\dagger}$ Randall Q. Snurr, ${ }^{\perp}$ Joseph T. Hupp, ${ }^{\dagger}$ Taner Yildirim, ${ }^{*},+,,{ }^{\prime}$ Omar K. Farha, ${ }^{* \dagger}$ and Chad A. Mirkin*, ${ }^{* \dagger}$

${ }^{\dagger}$ Department of Chemistry and International Institute for Nanotechnology and ${ }^{\perp}$ Department of Chemical \& Biological Engineering, Northwestern University, 2145 Sheridan Road, Evanston, Illinois 60208, United States

${ }^{\ddagger}$ NIST Center for Neutron Research, National Institute of Standards and Technology, Gaithersburg, Maryland 20899, United States

${ }^{\S}$ Department of Materials Science and Engineering, University of Pennsylvania, Philadelphia, Pennsylvania 19104, United States

Supporting Information

ABSTRACT: A Cu-carborane-based metal-organic framework (MOF), NU-135, which contains a quasi-spherical para-carborane moiety, has been synthesized and characterized. NU-135 exhibits a pore volume of $1.02 \mathrm{~cm}^{3} / \mathrm{g}$ and a gravimetric BET surface area of ca. 2600 $\mathrm{m}^{2} / \mathrm{g}$, and thus represents the first highly porous carborane-based MOF. As a consequence of the unique geometry of the carborane unit, NU-135 has a very high volumetric BET surface area of ca. $1900 \mathrm{~m}^{2} / \mathrm{cm}^{3} . \mathrm{CH}_{4}, \mathrm{CO}_{2}$, and $\mathrm{H}_{2}$ adsorption isotherms were measured over a broad range of pressures and temperatures and are in good agreement with computational predictions. The methane storage capacity of NU-135 at $35 \mathrm{bar}$ and $298 \mathrm{~K}$ is ca. $187 \mathrm{v}_{\mathrm{STP}} / \mathrm{v}$. At $298 \mathrm{~K}$, the pressure required to achieve a methane storage density comparable to that of a compressed natural gas ( $\mathrm{CNG}$ ) tank pressurized to 212 bar, which is a typical storage

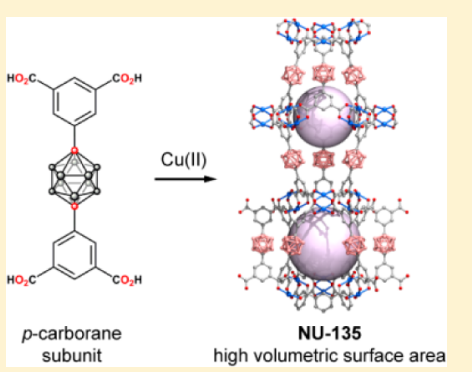
pressure, is only 65 bar. The methane working capacity $(5-65 \mathrm{bar})$ is $170 \mathrm{v}_{\mathrm{STP}} / \mathrm{v}$. The volumetric hydrogen storage capacity at 55 bar and $77 \mathrm{~K}$ is $49 \mathrm{~g} / \mathrm{L}$. These properties are comparable to those of current record holders in the area of methane and hydrogen storage. This initial example lays the groundwork for carborane-based materials with high surface areas.

KEYWORDS: carborane, boron, MOF, metal-organic framework, coordination polymer, porous, hydrogen, methane

\section{INTRODUCTION}

Nanoporous materials such as metal-organic frameworks (MOFs) with tailorable pore volumes, high internal surface areas, ${ }^{1,2}$ and chemical diversity form an important emerging class of materials that are potentially useful in a wide range of applications including ion exchange, ${ }^{3}$ catalysis, ${ }^{4,5}$ gas separation, ${ }^{6-8}$ sensing, ${ }^{9}$ and storage. ${ }^{10-12}$ In particular, MOFs have attracted great interest for onboard hydrogen and methane storage in vehicles, which is a long-standing goal for those interested in energy independence and the protection of the environment. Over the past decade, significant progress has been made toward building new classes of MOFs with desired material characteristics. This has been achieved via, for example, the tailoring of pore geometry, volume, surface area, and density, and by the incorporation of unsaturated metal centers. $^{13,14}$ Control over these parameters is crucial for realizing materials with high gas uptake capacity.

Polyhedral boranes and heteroboranes are a unique class of cluster compounds with properties and geometries that are not accessible with carbon-based systems. ${ }^{15}$ Among the polyhedral boranes, the family of isomeric icosahedral dicarbaboranes (closo- $\left.\mathrm{C}_{2} \mathrm{~B}_{10} \mathrm{H}_{12}\right)^{15}$ and their metallo-derivatives ${ }^{16}$ have received much attention because of their varied chemistry, ${ }^{17}$ redox properties, $^{18}$ thermal stability, and their potential for applications in the areas of medicine ${ }^{19}$ and materials chemistry. ${ }^{15}$ Recently we reported a series of MOFs that are derived from closo-1,12- $\mathrm{C}_{2} \mathrm{~B}_{10} \mathrm{H}_{12}$ (para-carborane). The carborane-based MOFs displayed exceptional thermal stability and large $\mathrm{CO}_{2} / \mathrm{CH}_{4}$ and $\mathrm{CO}_{2} / \mathrm{N}_{2}$ adsorption selectivities. ${ }^{7,8,20-22}$ However, the pore volumes and internal surface areas of these carborane-based MOFs were relatively small, thus limiting their usefulness in gas storage applications. Here we report a new copper(II)-carborane-based MOF in which the unique icosahedral structure of the carborane-derived ligand core leads to a combination of pore volume and high volumetric surface area that is conducive to high methane and hydrogen storage capacities.

\section{RESULTS AND DISCUSSION}

To create a new carborane-based MOF with a large pore volume and surface area, a relatively long boron-rich ligand was synthesized that consists of a central $p$-carborane unit and two isophthalic acid groups $\left(\mathbf{L H}_{4}\right)($ Scheme 1$)$. It has been shown that organic-based bis(isophthalic acid) ligands of this type produce an isoreticular family of copper(II)-based MOFs, known as the NOTT-100 series, with the nbo topology. ${ }^{23-28}$

Received: June 27, 2013

Revised: $\quad$ August 2, 2013

Published: August 3, 2013 
Scheme 1. Synthesis of the Carborane-Bis(isophthalic acid) Ligand $\left(\mathrm{LH}_{4}\right)$ Used to Construct NU-135. ${ }^{a}$

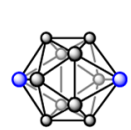

p-carborane
$\mathrm{HO}_{2} \mathrm{C}$
$\mathrm{HO}_{2}$

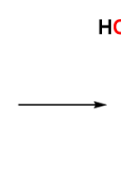

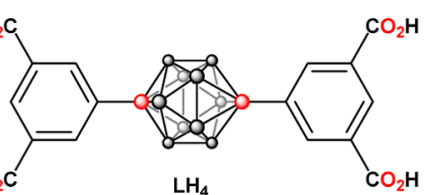

$\mathrm{LH}_{4}$

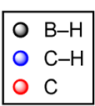

O C
${ }^{a}$ Reaction conditions: (i) $n$-BuLi, THF; $\mathrm{CuCl}$, THF -40 to $70{ }^{\circ} \mathrm{C}$; diethyl 5-iodoisophthalate, $\mathrm{Pd}\left(\mathrm{PPh}_{3}\right)_{4}, \mathrm{NMP}, 100{ }^{\circ} \mathrm{C}, 16 \mathrm{~h}(42 \%)$. (ii) $\mathrm{LiOH}(1 \mathrm{M}), \mathrm{THF} / \mathrm{H}_{2} \mathrm{O} 2: 1, \mathrm{rt}, 36 \mathrm{~h} ; \mathrm{H}_{3} \mathrm{O}^{+}(84 \%)$.

This family of MOFs shows great promise in the areas of methane and hydrogen storage. The extended carborane-based ligand $\mathbf{L H}_{4}$ was synthesized via $\mathrm{Cu}(\mathrm{I})-\mathrm{Pd}(\mathrm{II})$ coupling chemistry adapted from a report by Schöberl et al. ${ }^{29}$ The synthesis and characterization are described in the Supporting Information. The solvothermal reaction between $\mathrm{Cu}\left(\mathrm{NO}_{3}\right)_{2}$. $2.5 \mathrm{H}_{2} \mathrm{O}$ and $\mathbf{L H}_{4}$ in $\mathrm{DMF}$ at $80{ }^{\circ} \mathrm{C}$ for $16 \mathrm{~h}$ yielded blue crystals (NU-135). Single-crystal X-ray diffraction analysis revealed that NU-135 crystallizes in the $R \overline{3} m$ space group and has the nbo topology (Figure 1). The framework nodes consist of $\mathrm{Cu}_{2}$ units coordinated by the carboxylate groups of $\mathbf{L}^{4-}$ in a paddlewheel configuration. As synthesized, each axial coordination site is occupied by a water molecule. The network is noncatenated, and there are two distinct cages, each with $D_{3 d}$ symmetry, as shown in Figure $1 \mathrm{~b}$. Importantly, the $p$-carborane moieties, which are approximately equal in length to a phenylene group, are quasi-spherical and project into the pores of the framework. This has important implications regarding surface area, pore volume, and gas uptake (vide infra). The experimental unit cell dimensions are $a=b=$ 18.6953(7) $\AA$ and $c=39.1379(17) \AA$. The solvent-free structure of NU-135 has a density of $0.751 \mathrm{~g} / \mathrm{cm}^{3}$. This value is used to convert the measured hydrogen and methane storage capacities to volumetric units (vide infra). The crystallographically derived structure was used to simulate $\mathrm{N}_{2}, \mathrm{CH}_{4}$, $\mathrm{CO}_{2}$, and $\mathrm{H}_{2}$ gas adsorption (see the Supporting Information for simulation details).

After the guest solvent molecules were removed via supercritical $\mathrm{CO}_{2}$ (see the Supporting Information for activation details), ${ }^{30,31}$ the samples were further activated thermally by heating slowly to $100^{\circ} \mathrm{C}$ for $3-5 \mathrm{~h}$ under dynamic vacuum. The porosity was determined by nitrogen adsorption at $77 \mathrm{~K}$ as shown in Figure 2. The experimental and calculated Brunauer-Emmett-Teller ${ }^{32}$ (BET) surface areas are 2530 and $2700 \mathrm{~m}^{2} / \mathrm{g}$, respectively. The pore volume of NU-135, derived from the measured $\mathrm{N}_{2}$ isotherm, is $1.02 \mathrm{~cm}^{3} / \mathrm{g}$ (77\% empty space), which is somewhat higher than the calculated value of $0.9 \mathrm{~cm}^{3} / \mathrm{g}$ (68\% porosity) by PLATON. ${ }^{33,34}$ Nevertheless, the nitrogen isotherm measurements were repeated on several batches of samples using different apparatus (Quantachrome) in addition to our custom high-pressure Sievert and essentially identical results were obtained (see Figure S9 in the Supporting Information).

Because of the close similarities in unit-cell parameters, direct comparisons may be drawn between NU-135 and members of the isoreticular family of MOFs based on $p$-phenylene bis(isophthalic acid)s known as the NOTT-100 series. ${ }^{23}$ As mentioned above, the $p$-carborane moiety is approximately equal in length to a phenylene group and, consequently, the unit-cell volume of NU-135 is only $2.5 \%$ greater than that of terphenyl derivative NOTT-101. Importantly, the volumetric (a)

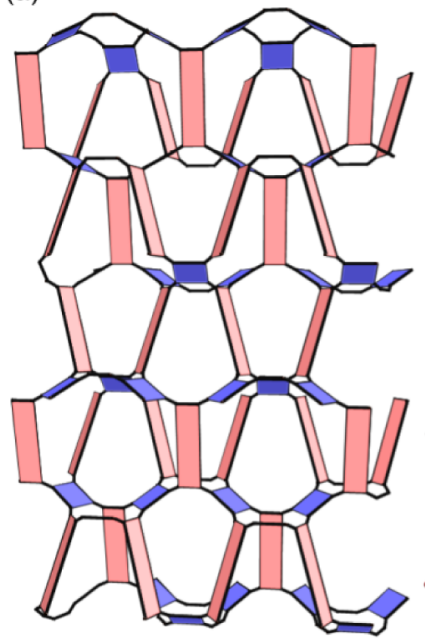

(b)

(c)

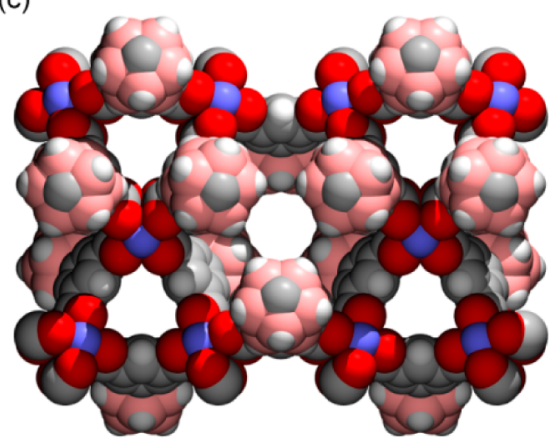

Figure 1. Representations of the crystal structure of NU-135. (a) Simplified nbo network viewed along the $a b$ plane. Blue squares $=\mathrm{Cu}_{2}$ paddlewheels; pink rectangles $=$ carborane bis(isophthalic acid) ligands. (b) Detail of pores, viewed along the $a b$ plane. Lilac spheres indicate the largest sphere-shaped voids that can be found within the evacuated MOF as defined by the internal van der Waals surface of the material. Hydrogen atoms removed for clarity. (c) Space-filling representation, viewed along the $c$ axis, illustrating the carboranelined pores. Atom code: $\mathrm{C}=$ gray; $\mathrm{H}=$ white; $\mathrm{O}=$ red; $\mathrm{B}=$ pink; $\mathrm{Cu}=$ blue.

surface area (via BET measurement) is ca. $30 \%$ greater (i.e., 1900 and $1460 \mathrm{~m}^{2} / \mathrm{cm}^{3}$ for NU-135 and NOTT-101, respectively), ${ }^{23,28}$ yet the crystallographically derived fraction of free space within NU-135 (68\%) is only slightly smaller than that of NOTT-101 (71\%). These differences in geometry are a consequence of the globular $p$-carborane subunit. It is important to note here that this effect seems unique to the incorporation of the carborane unit. For comparison, the addition of two or four methyl substituents to the central phenylene group of NOTT-101, to produce NOTT-106 and $-107,{ }^{23,25}$ respectively, reduces the fraction of free space within the frameworks, as expected. However, the addition of the methyl groups also significantly reduces the volumetric surface area (e.g., 1460 and $1340 \mathrm{~m}^{2} / \mathrm{cm}^{3}$ for NOTT-101 and NOTT107 , respectively).

Temperature-dependent high-pressure adsorption measurements were performed at the Center for Neutron Research, National Institute of Standards and Technology (NIST), using a computer-controlled Sieverts apparatus, the details of which have been published elsewhere ${ }^{35}$ and are briefly discussed in the Supporting Information. The gas uptake properties of NU135 at $298 \mathrm{~K}$ for $\mathrm{N}_{2}, \mathrm{CO}_{2}$, and $\mathrm{CH}_{4}$ are shown in Figure 3. 


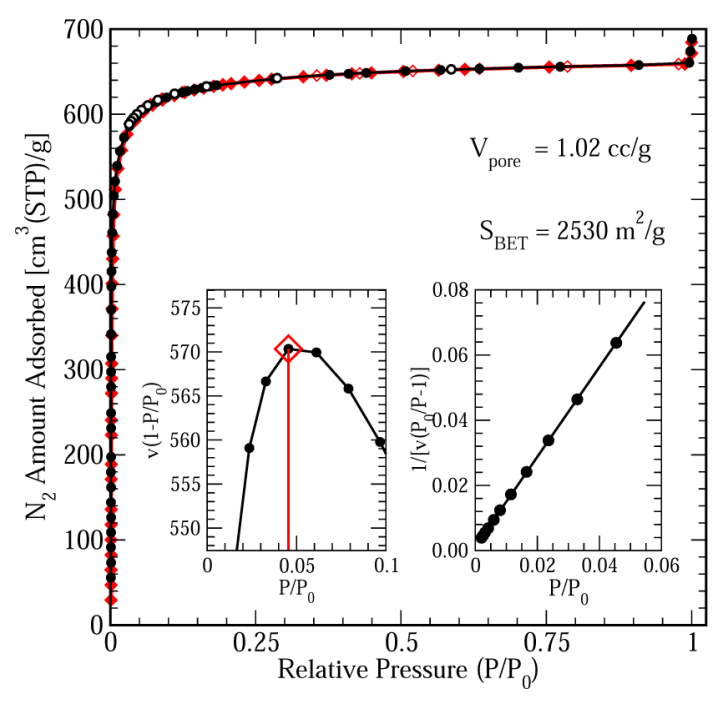

Figure 2. Nitrogen isotherms for NU-135 at $77 \mathrm{~K}$ before (black) and after (red) $\mathrm{CH}_{4}, \mathrm{CO}_{2}$, and $\mathrm{H}_{2}$ adsorption measurements, indicating no sample degradation over the course of the adsorption cycles. The inset on the left shows the consistency plot used to determine the pressure range for BET fitting, which is shown in the inset on the right.

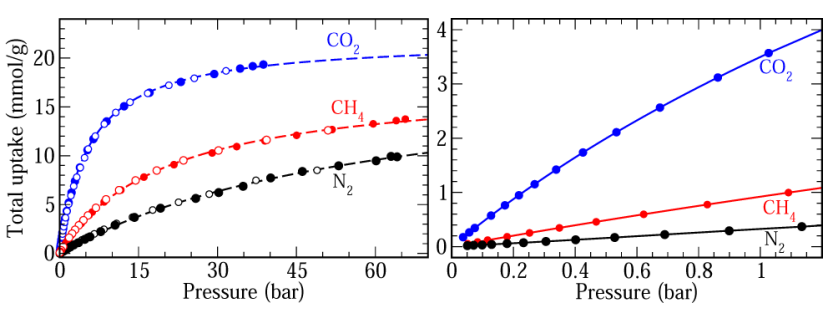

Figure 3. Left: High-pressure gas adsorption measurements on NU135 for $\mathrm{CO}_{2}, \mathrm{CH}_{4}$, and $\mathrm{N}_{2}$ at $298 \mathrm{~K}$. The dashed-lines are a simple one-site Langmuir fit to the data. Right: Low-pressure ranges of the isotherms, indicating large $\mathrm{CO}_{2} / \mathrm{CH}_{4}$ and $\mathrm{CO}_{2} / \mathrm{N}_{2}$ selectivities.

Although the previously reported carborane-based MOFs exhibited low total gas uptake, they exhibited large $\mathrm{CO}_{2} / \mathrm{CH}_{4}$ selectivities of up to 17 at 0.5 bar. NU-135 exhibits much larger total gas uptake compared to earlier carborane-based MOFs but the $\mathrm{CO}_{2} / \mathrm{CH}_{4}$ selectivity is reduced to ca. 4 at 0.5 bar (Figure 3 ). In the case of $\mathrm{CO}_{2} / \mathrm{N}_{2}$ selectivity, NU-135 exhibits a relatively large value of 14.5 at 0.15 bar, which could be important for carbon capture applications from flue-gas. As shown in Figure 3, NU-135 exhibits a high capacity for methane at high pressures. This capacity is comparable to MOFs that exhibit high methane storage, such as UTSA-20, ${ }^{36}$ PCN-14, ${ }^{24} \mathrm{NU}-111,{ }^{37}$ and NU-125. ${ }^{38}$ We observed an absolute methane storage capacity of $230 \mathrm{v}_{\mathrm{STP}} / \mathrm{v}$ (i.e., ca. $10.3 \mathrm{mmol} / \mathrm{cm}^{3}$ or $13.7 \mathrm{mmol} / \mathrm{g}$ ) at $65 \mathrm{bar}$, which corresponds to the amount of methane stored in a CNG tank at 212 bar. $^{39}$ Thus, NU-135 effectively reduces the pressure required for useful loading (230 $\mathrm{v}_{\mathrm{STP}} / \mathrm{v}$ ) by a factor of 3.3 , down to 65 bar. This is a potentially important advance as it demonstrates the ability of a material to absorb natural gas to the extent where it may become commercially attractive. The stability of NU-135 toward multiple cycles of methane adsorption/desorption was tested (see Figure S14 in the Supporting Information). There is no sample degradation at 35 or 65 bar over eight cycles, and the variation of the total adsorption at 65 bar is less than $1.5 \%$, which is within the error of the measurements.
Ultimately, the deliverable methane capacity determines the driving range of a natural gas vehicle (NGV). In this case it is important for a porous material to have low capacity in the ca. 5 bar range, and high capacity in the $60-70$ bar range. ${ }^{40}$ The adsorption isotherm of NU-135 has a relatively shallow gradient at low pressure; taking 5 bar as the specific lower pressure limit and 65 bar as the upper limit, the deliverable capacity of NU-135 is ca. $170 \mathrm{v}_{\mathrm{STP}} / \mathrm{v}$ at $298 \mathrm{~K}$ (Figure 3). This value is comparable to MOFs that show the most promise for deliverable methane storage (e.g., UTSA-20 and PCN14). ${ }^{24,35,37,38}$ These properties may arise from the icosahedral carborane unit which provides an almost ideal balance between surface area, pore size and pore volume. Furthermore, it is reasonable to suggest that the inverted polarity of the $\mathrm{B}-\mathrm{H}$ bonds and correspondingly hydridic nature of the carboranebound hydrogen atoms impart properties to the framework that are not accessible via regular hydrocarbon chemistry.

In addition to performing high-pressure isotherm measurements at $298 \mathrm{~K}$, we also measured high-pressure $\mathrm{CH}_{4}$ adsorption over a wide range of temperatures on the same sample (Figure 4). Low temperature adsorption isotherm
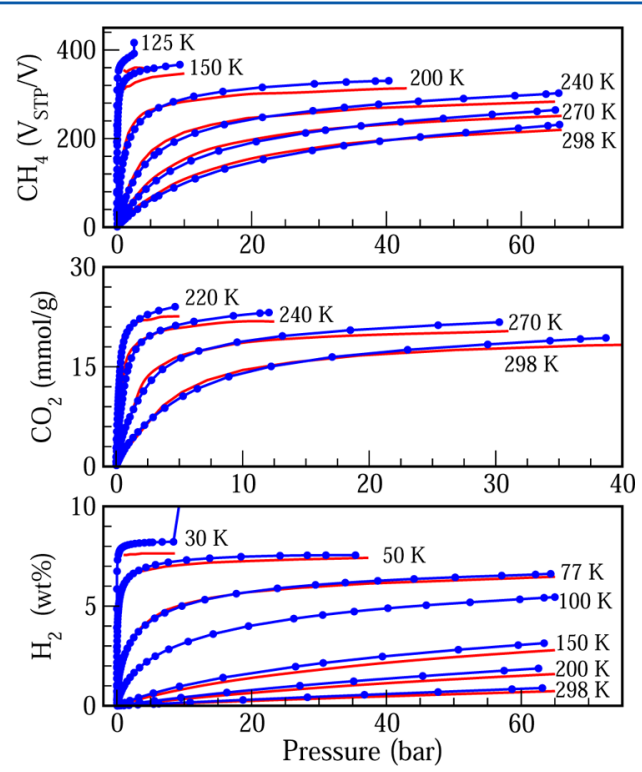

Figure 4. Experimental (blue) and simulated (red) high-pressure absolute gas adsorption isotherms for NU-135 at several temperatures.

measurements are indispensable because they provide information on the maximum gas storage capacity of the material. For NU-135, we obtained a maximum methane uptake of ca. $392 \mathrm{v}_{\mathrm{STP}} / \mathrm{v}(23.3 \mathrm{mmol} / \mathrm{g})$ at $125 \mathrm{~K}$, which effectively corresponds to the upper limit for the amount of gas that can be adsorbed under very large external pressures at ambient temperature. The observed maximum $\mathrm{CH}_{4}$ uptake is very close to the upper limit of $432 \mathrm{v}_{\mathrm{STP}} / \mathrm{v}(25.7 \mathrm{mmol} / \mathrm{g})$ as obtained from taking the nitrogen-based pore volume and assuming liquid methane density at $125 \mathrm{~K}$. This suggests that methane is able to access most of the pores in NU-135 that are accessible to nitrogen at $77 \mathrm{~K}$.

$\mathrm{CO}_{2}$, and $\mathrm{H}_{2}$ adsorption isotherms were also measured over similarly wide pressure and temperature ranges (see Figure 4). The maximum excess $\mathrm{H}_{2}$ uptake at $77 \mathrm{~K}$ is about 5.1 wt \% (see Figure S13 in the Supporting Information), which is in good agreement with that expected from "Chahine's rule" 1 wt $\%$ for every $500 \mathrm{~m}^{2} / \mathrm{g}$ ). This empirical rule is observed for 
most carbon or carbon-rich nanoporous materials in which van der Waals interactions are the dominant mechanism for adsorption. In terms of absolute volumetric hydrogen uptake, an impressive maximum value of ca. $49 \mathrm{~g} / \mathrm{L}$ is obtained above ca. 55 bar at $77 \mathrm{~K}$. This value places NU-135 among the highest performing MOFs for volumetric hydrogen storage. ${ }^{10}$ NU-135 also exhibits significant $\mathrm{CO}_{2}$ uptake at high pressures. The maximum $\mathrm{CO}_{2}$ uptake at $220 \mathrm{~K}$ is $24.6 \mathrm{mmol} / \mathrm{g}$, which is in good agreement with the upper limit of $27.2 \mathrm{mmol} / \mathrm{g}$ as estimated from the nitrogen pore volume and liquid density of $\mathrm{CO}_{2}$ at this temperature. The $\mathrm{CO}_{2}$ uptake at room temperature and $30 \mathrm{bar}$ is ca. $18.5 \mathrm{mmol} / \mathrm{g}$, corresponding to $75 \%$ of the total pore volume. At 0.15 bar and $298 \mathrm{~K}$ (i.e., a condition that approximates flue gas from coal power plants), the $\mathrm{CO}_{2}$ uptake is about 3 wt \%. This value is lower than that of MOF-74, which contains open metal sites, but higher than the uptakes exhibited by many MOFs reported in a recent $\mathrm{CO}_{2}$ screening survey. ${ }^{42}$ The simulated isotherms for $\mathrm{H}_{2}, \mathrm{CH}_{4}$, and $\mathrm{CO}_{2}$ are in good agreement with the experimental isotherms (Figure 4).

The natures of the adsorption sites and gas-framework interactions in NU-135 were probed by using the ClausiusClapeyron equation to extract the isosteric heats of adsorption $\left(Q_{\mathrm{st}}\right)$ from the absolute isotherms measured at different temperatures (Figure 5, details in the Supporting Informa-

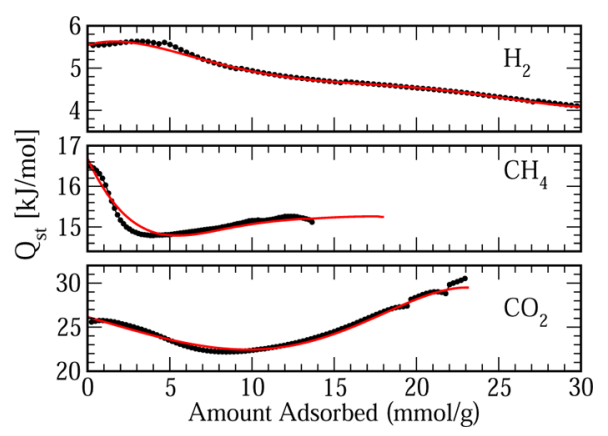

Figure 5. Isosteric heats of adsorption $\left(Q_{s t}\right)$ as a function of gas loading in $\mathrm{mmol}$ (gas) $/ \mathrm{g}(\mathrm{NU}-135)$. The red lines are from virial fitting. The black dotted lines are from original isotherm data with spline (without any fitting).

tion). ${ }^{1}$ The magnitudes of the $Q_{s t}$ values are comparable with other $\mathrm{Cu}$-paddlewheel-based MOFs. ${ }^{23,35}$ In the cases of $\mathrm{CO}_{2}$ and $\mathrm{CH}_{4}$, the $Q_{\text {st }}$ values are initially high, drop, and then increase. This is probably due to significant gas-gas interactions which become important at higher loading. In the case of hydrogen, the $Q_{s t}$ stays constant initially (ca. $5.6 \mathrm{~kJ} /$ mol) and then decreases to ca. $4 \mathrm{~kJ} / \mathrm{mol}$ at greater $\mathrm{H}_{2}$ loadings. This may be due to negligible $\mathrm{H}_{2}-\mathrm{H}_{2}$ interactions.

\section{CONCLUSIONS}

The interplay between volumetric surface area and pore volume makes an important contribution to volumetric adsorption in MOFs. Icosahedral carboranes possess a unique quasi-spherical geometry that is inaccessible using organic chemistry, and can thus be used to create MOFs with pore geometries that cannot be obtained using organic ligands. Thus, compared to an isostructural MOF that contains a phenylene group rather than a $p$-carborane group, NU-135 has a slightly reduced pore volume but greatly enhanced volumetric surface area. This is reflected by the exceptionally high volumetric hydrogen and methane uptake exhibited by NU-135. An important aspect of this work is the ease with which the carborane subunit may be incorporated into larger structures. This allows for specific frameworks, in this case the isoreticular NOTT-100 series, to be targeted and modified with the carborane subunit in order to increase the volumetric surface area. NU-135, which was synthesized via this approach, has approximately twice the pore volume and surface area of previously reported carborane-based MOFs, and thus represents the first highly porous carboranebased MOF. The incorporation of the carborane polyhedra into other high-performance MOFs is an exciting prospect, and will hopefully lead to materials with record-breaking gas sorption properties. Furthermore, the simulations agree very well with the experimental measurements over a wide pressure and temperature range, as well as across several different sorbate molecules, thus demonstrating the applicability of simulations in the cases of MOFs that contain exotic components such as polyhedral carboranes. This novel strategy, in which a carborane moiety is employed to greatly increase volumetric surface area, will allow us and others to expand the current capability of porous materials for gas storage applications.

\section{ASSOCIATED CONTENT}

\section{Supporting Information}

General procedures, materials, and instrumentation; synthesis, characterization $\left({ }^{1} \mathrm{H},{ }^{13} \mathrm{C},{ }^{11} \mathrm{~B}\right.$ NMR, HR-MS, elemental analysis), and crystallographic information files (CIF) for $\mathbf{L H}_{4}, \mathbf{L E t}_{4}$, and NU-135; PXRD, adsorption excess isotherms, $\mathrm{BET}$ analysis, and simulation details; support disclaimers. This material is available free of charge via the Internet at http:// pubs.acs.org.

\section{AUTHOR INFORMATION}

\section{Corresponding Author}

*E-mail: chadnano@northwestern.edu (C.A.M.); o-farha@ northwestern.edu (O.K.F.); taner@seas.upenn.edu (T.Y.).

\section{Author Contributions}

R.D.K. and T.Y. contributed equally to this work.

\section{Notes}

The authors declare the following competing financial interest: O.K.F., C.E.W., R.Q.S., and J.T.H. hold equity interests in NuMat Technologies, a company that is pursuing commercialization of MOFs for methane storage.

\section{ACKNOWLEDGMENTS}

C.A.M. acknowledges support from DoD/NSSEFF/NPS Awards N00244-09-1-0012 and N00244-09-1-0071, U.S. Army Award W911NF-11-1-0229, NSF award CHE-1149314, Department of the Navy/ONR award N00014-11-1-0729, and the NERC/EFRC DOE/Office of Science/Office of Basic Energy Sciences Award DE-SC0000989. O.K.F., J.T.H., and R.Q.S. thank DOE ARPA-E, and the Stanford Global Climate and Energy Project for support of work relevant to methane, and $\mathrm{CO}_{2}$, respectively. T.Y. acknowledges support by the U.S. Department of Energy through BES Grant DE-FG0208ER46522. C.E.W. gratefully acknowledges support from a Ryan Fellowship from the Northwestern University International Institute for Nanotechnology. JEM is supported by a DOE EERE postdoctoral research award under DOE Contract DE-AC05-060R23100. Computational work was supported through the resources provided by Information Technology at Northwestern University as part of its shared cluster program, Quest. 


\section{REFERENCES}

(1) Farha, O. K.; Eryazici, I.; Jeong, N. C.; Hauser, B. G.; Wilmer, C. E.; Sarjeant, A. A.; Snurr, R. Q.; Nguyen, S. T.; Yazaydın, A. Ö.; Hupp, J. T. J. Am. Chem. Soc. 2012, 134, 15016-15021.

(2) Sarkisov, L. Adv. Mater. 2012, 24, 3130-3133.

(3) Min, K. S.; Suh, M. P. J. Am. Chem. Soc. 2000, 122, 6834-6840.

(4) Lee, J.; Farha, O. K.; Roberts, J.; Scheidt, K. A.; Nguyen, S. T.; Hupp, J. T. Chem. Soc. Rev. 2009, 38, 1450-1459.

(5) Ma, L.; Abney, C.; Lin, W. Chem. Soc. Rev. 2009, 38, 1248-1256.

(6) Li, J.-R.; Kuppler, R. J.; Zhou, H.-C. Chem. Soc. Rev. 2009, 38, 1477-1504.

(7) Bae, Y.-S.; Farha, O. K.; Spokoyny, A. M.; Mirkin, C. A.; Hupp, J. T.; Snurr, R. Q. Chem. Commun. 2008, 4135-4137.

(8) Bae, Y.-S.; Spokoyny, A. M.; Farha, O. K.; Snurr, R. Q.; Hupp, J. T.; Mirkin, C. A. Chem. Commun. 2010, 46, 3478-3480.

(9) Kreno, L. E.; Leong, K.; Farha, O. K.; Allendorf, M.; Van Duyne, R. P.; Hupp, J. T. Chem. Rev. 2012, 112, 1105-1125.

(10) Suh, M. P.; Park, H. J.; Prasad, T. K.; Lim, D.-W. Chem. Rev. 2012, 112, 782-835.

(11) Farha, O. K.; Yazaydın, A. Ö.; Eryazici, I.; Malliakas, C. D.; Hauser, B. G.; Kanatzidis, M. G.; Nguyen, S. T.; Snurr, R. Q.; Hupp, J. T. Nat. Chem. 2010, 2, 944-948.

(12) Furukawa, H.; Ko, N.; Go, Y. B.; Aratani, N.; Choi, S. B.; Choi, E.; Yazaydın, A. Ö.; Snurr, R. Q.; O’Keeffe, M.; Kim, J.; Yaghi, O. M. Science 2010, 329, 424-428.

(13) Sumida, K.; Stück, D.; Mino, L.; Chai, J.-D.; Bloch, E. D.; Zavorotynska, O.; Murray, L. J.; Dincă, M.; Chavan, S.; Bordiga, S.; Head-Gordon, M.; Long, J. R. J. Am. Chem. Soc. 2013, 135, 10831091.

(14) Wu, H.; Zhou, W.; Yildirim, T. J. Am. Chem. Soc. 2009, 131, 4995-5000.

(15) Grimes, R. N. Carboranes, second ed.; Elsevier: Amsterdam, 2011.

(16) Hawthorne, M. F.; Young, D. C.; Andrews, T. D.; Howe, D. V.; Pilling, R. L.; Pitts, A. D.; Reintjes, M.; Warren, L. F.; Wegner, P. A. J. Am. Chem. Soc. 1968, 90, 879-896.

(17) Wedge, T. J.; Hawthorne, M. F. Coord. Chem. Rev. 2003, 240, 111-128.

(18) Lee, M. W.; Farha, O. K.; Hawthorne, M. F.; Hansch, C. H. Angew. Chem., Int. Ed. 2007, 46, 3018-3022.

(19) Valliant, J. F.; Guenther, K. J.; King, A. S.; Morel, P.; Schaffer, P.; Sogbein, O. O.; Stephenson, K. A. Coord. Chem. Rev. 2002, 232, 173230.

(20) Farha, O. K.; Spokoyny, A. M.; Mulfort, K. L.; Galli, S.; Hupp, J. T.; Mirkin, C. A. Small 2009, 5, 1727-1731.

(21) Farha, O. K.; Spokoyny, A. M.; Mulfort, K. L.; Hawthorne, M. F.; Mirkin, C. A.; Hupp, J. T. J. Am. Chem. Soc. 2007, 129, 1268012681 .

(22) Spokoyny, A. M.; Farha, O. K.; Mulfort, K. L.; Hupp, J. T.; Mirkin, C. A. Inorg. Chim. Acta 2010, 364, 266-271.

(23) Yan, Y.; Lin, X.; Yang, S.; Blake, A. J.; Dailly, A.; Champness, N. R.; Hubberstey, P.; Schröder, M. Chem. Commun. 2009, 1025-1027. (24) Ma, S.; Sun, D.; Simmons, J. M.; Collier, C. D.; Yuan, D.; Zhou, H.-C. J. Am. Chem. Soc. 2007, 130, 1012-1016.

(25) Wilmer, C. E.; Leaf, M.; Lee, C. Y.; Farha, O. K.; Hauser, B. G.; Hupp, J. T.; Snurr, R. Q. Nature Chem. 2011, 4, 83-89.

(26) Chen, B.; Ockwig, N. W.; Millward, A. R.; Contreras, D. S.; Yaghi, O. M. Angew. Chem., Int. Ed. 2005, 44, 4745-4749.

(27) Hu, Y.; Xiang, S.; Zhang, W.; Zhang, Z.; Wang, L.; Bai, J.; Chen, B. Chem. Commun. 2009, 7551-7553.

(28) Lin, X.; Jia, J.; Zhao, X.; Thomas, K. M.; Blake, A. J.; Walker, G. S.; Champness, N. R.; Hubberstey, P.; Schröder, M. Angew. Chem., Int. Ed. 2006, 45, 7358-7364.

(29) Schöberl, U.; Magnera, T. F.; Harrison, R. M.; Fleischer, F.; Pflug, J. L.; Schwab, P. F. H.; Meng, X.; Lipiak, D.; Noll, B. C.; Allured, V. S.; Rudalevige, T.; Lee, S.; Michl, J. J. Am. Chem. Soc. 1997, 119, 3907-3917.

(30) Farha, O. K.; Hupp, J. T. Acc. Chem. Res. 2010, 43, 1166-1175.
(31) Nelson, A. P.; Farha, O. K.; Mulfort, K. L.; Hupp, J. T. J. Am. Chem. Soc. 2008, 131, 458-460.

(32) Brunauer, S.; Emmett, P. H.; Teller, E. J. Am. Chem. Soc. 1938, 60, 309-319.

(33) Spek, A. L. Acta Crystallogr., Sect. D 2009, 65, 148-155. The van der Waals radii used in the analysis: $\mathrm{C}, 1.70 ; \mathrm{H}, 1.2 ; \mathrm{B}, 1.63 ; \mathrm{Cu}$, $1.4 ; \mathrm{N}, 1.5 ; \mathrm{O}, 1.52$.

(34) This result is not unexpected, as crystallographically derived porosities often underestimate those obtained via adsorption experiments by up to $20 \%$.

(35) Zhou, W.; Wu, H.; Hartman, M. R.; Yildirim, T. J. Phys. Chem. C 2007, 111, 16131-16137.

(36) Guo, Z.; Wu, H.; Srinivas, G.; Zhou, Y.; Xiang, S.; Chen, Z.; Yang, Y.; Zhou, W.; O'Keeffe, M.; Chen, B. Angew. Chem., Int. Ed. 2011, 50, 3178-3181.

(37) Peng, Y.; Srinivas, G.; Wilmer, C. E.; Eryazici, I.; Snurr, R. Q.; Hupp, J. T.; Yildirim, T.; Farha, O. K. Chem. Commun. 2013, 49, 2992-2994.

(38) Wilmer, C. E.; Farha, O. K.; Yildirim, T.; Eryazici, I.; Krungleviciute, V.; Sarjeant, A. A.; Snurr, R. Q.; Hupp, J. T. Energy Environ. Sci. 2013, 6, 1158-1163.

(39) The definition of STP used in this paper is $273 \mathrm{~K}$ and $1 \mathrm{~atm}, 1$ $\mathrm{mmol} / \mathrm{g}$ means $22.414 \mathrm{~cm}^{3} / \mathrm{g}$.

(40) Makal, T. A.; Li, J.-R.; Lu, W.; Zhou, H.-C. Chem. Soc. Rev. 2012, 41, 7761-7779.

(41) Poirier, E.; Chahine, R.; Bose, T. K. Int. J. Hydrogen Energy 2001, 26, 831-835.

(42) Yazaydın, A. Ö.; Snurr, R. Q.; Park, T.-H.; Koh, K.; Liu, J.; LeVan, M. D.; Benin, A. I.; Jakubczak, P.; Lanuza, M.; Galloway, D. B.; Low, J. J.; Willis, R. R. J. Am. Chem. Soc. 2009, 131, 18198-18199. 